\title{
Artificial Potential Field Algorithm for Obstacle Avoidance in UAV Quadrotor for Dynamic Environment
}

\author{
Alfian Ma'arif \\ Universitas Ahmad Dahlan \\ Yogyakarta, Indonesia \\ alfianmaarif@ee.uad.ac.id \\ https://orcid.org/0000-0002-3482-971X \\ *Corresponding Author \\ Aninditya Anggari Nuryono \\ Universitas Mulia \\ Balikpapan, Indonesia \\ https://orcid.org/0000-0001-8841-6585
}

\author{
Wahyu Rahmaniar \\ National Central University \\ Taiwan \\ https://orcid.org/0000-0002-6902-5455
}

Rania Majdoubi

Mohammed V University

Rabat, Marocco

https://orcid.org/0000-0003-0967-5955

\author{
Marco Antonio Márquez Vera \\ Polytechnic University of Pachuca \\ Pachuca, Mexico \\ https://orcid.org/0000-0002-2969-9084
}

\author{
Abdullah Çakan \\ Konya Technical University \\ Konya, Turkey \\ http://orcid.org/0000-0003-3923-4069
}

\begin{abstract}
Artificial potential field (APF) is the effective realtime guide, navigation, and obstacle avoidance for UAV Quadrotor. The main problem in APF is local minima in an obstacle or multiple obstacles. In this paper, some modifications and improvements of APF will be introduced to solve oneobstacle local minima, two-obstacle local minima, Goal Not Reachable Near Obstacle (GNRON) and dynamic obstacle. The result shows that the improved APF gave the best result because it made the system reach the goal position in all of the examinations. Meanwhile, the APF with virtual force has the fastest time to reach the goal; however, it still has a problem in GNRON. It can be concluded that the APF needs to be modified in its algorithm to pass all of the local minima problems.
\end{abstract}

Keywords-Artificial Potential Field, Unmanned Aerial Vehicle, Path Planning, Obstacle Avoidance, Dynamic Environment

\section{INTRODUCTION}

An unmanned Aerial Vehicle (UAV) is an unmanned flying vehicle that is usually controlled remotely or autonomous [1]. One kind of UAV is Quadrotor that has four rotors for flying [2][3][4]. The advantage of a Quadrotor is that it can take off and land in a vertical position or Vertical Take Off and Landing (VTOL) [5][6][7]. Because of that, many researchers researched quadrotor, and it is important to do.

One of the essential sub-systems in UAV is path planning that will guide and navigate the robot to reach the goal with obstacle avoidance [8][9][10][11]. Some path planning methods have been proposed, such as the iteration method and the real-time method [12]. The iteration method, or heuristic method, can give better path planning but needs more time for computing to find good path planning [13]. Thus it will need more time for processing in a larger area. Meanwhile, the realtime method, or classical algorithm, does not need iteration and has simple mathematical equations [14]. Thus, it will need less time for processing [15].
Some methods that can be categorized into iteration methods for path planning are Ant Colony [16], Genetic Algorithm [17][18], Particle Swarm Optimization [19], Differential Evolution [20][21], and Membrane PseudoBacterial Potential Field [22], etc. [23]. Based on previous researches, it can be concluded that the iteration method can give good results for path planning; however, it is only applicable to a small area. If used in a large, dynamic environment and unknown area, it will need more time to process.

One of the real-time methods is Artificial Potential Field (APF) [24][25]. Khatib was the first to introduce the APF method for manipulators and mobile robots [26][27][28]. The APF can be implemented in mobile robots [29][30][31], flying robots [32], manipulator robots [33][34], and humanoid robot [35]. There are some modifications in APF that the researcher made. Based on those researches, it can be concluded that APF is good for real-time systems in a large, unknown environment and dynamic area but need some improvement [36][37][38][39].

APF have simple mathematic equation so that it need low computation. Thus it will suitable for real time application [40]. However, there is a main problem in the APF that is local minima [41]. There are some types of local minima, such as local minima in one obstacle, local minima in two obstacles [42], local minima in goal not reachable (GNRON) [43] [44][45] and dynamic or moving obstacle. However, most researchers only consent to solve one of those problems by modifying the algorithm [46]. For instance, Khatib et al. only focused on collision avoidance and moving obstacles [26][27], which can be extended to two obstacle local minima and GNRON local minima problems were not included in the discussions. Rizqi et al. [47] took one-obstacle and twoobstacle local minima as its focused problem and did not consider the GNRON problem. Sun et al. [48] researched most local minima problems; unfortunately, two obstacle local minima were not discussed in the research. 
Until now, the performance of those aforementioned methods to all local minima problems had not been studied yet. Therefore, this study aims to compare the performance of modified APF algorithms in challenging various obstacles with local minima. In the research, the conventional APF [26][27], modified APF [47], optimized APF [48], and APF with virtual force [49] will be compared to know its performances in navigating for a dynamic and unknown environment.

The paper will be written in the following structure. The first part is the introduction. Next, the second part is about the navigation process. The third part will discuss the Artificial Potential Field Algorithm. The fourth part contains simulation results and discussion. The last part is the conclusion.

\section{The NAvigation Process}

The proposed system is shown in Fig. 1. The APF algorithm has three inputs that are goal position, obstacle position, and robot position. In the research, the goal and obstacle position is written in the program. In real system, the goal position and robot position can be known by using an IMU sensor or GPS. The obstacle position can be known by using a distance sensor.

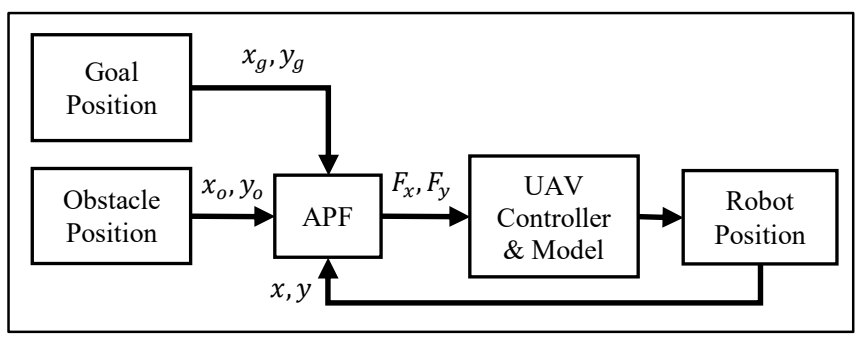

Fig. 1. Proposed System

The APF gives the robot reference position (setpoint). In the UAV, there are controllers that help the robot to reach the set point from APF. It can be a PID control [50], state feedback [49], fuzzy logic [51][52], or another controller [53][54][55].

\section{ARTIFICIAl Potential Field}

\section{A. Attractive Force of APF}

Commonly, APF consists of two forces; the first is the attractive force, and the second is the repulsive force. Attractive Force is the force that is used to navigate the robot to the goal. Suppose the $\mathbf{x}=\left[\begin{array}{ll}x & y\end{array}\right]^{T}$ is the $x y$-coordinate of the robot, the attractive function is

$$
U_{a t t}(\mathbf{x})=\frac{1}{2} k_{a}\left(\mathbf{x}-\mathbf{x}_{d}\right)^{2}
$$

where, $k_{a}$ is the attractive gain, $\mathbf{x}$ is the robot position vector, $\mathbf{x}_{d}$ is the goal position vector.

The attractive force is the gradient of attractive potential function as

$$
\begin{gathered}
F_{a t t}(\mathbf{x})=-\nabla U_{a t t}(\mathbf{x}) \\
=-k_{a}\left(\mathbf{x}-\mathbf{x}_{d}\right)
\end{gathered}
$$

\section{B. The Repulsive of $A P F$}

The repulsive force is the force that is used to avoid the obstacle. The repulsive potential function is

$$
U_{\text {rep }}=\left\{\begin{aligned}
\frac{1}{2} k_{r}\left(\frac{1}{\rho}-\frac{1}{\rho_{0}}\right)^{2}, & \text { if } \rho \leq \rho_{0} \\
0, & \text { if } \rho>\rho_{0}
\end{aligned}\right.
$$

where, $k_{r}$ is the repulsive gain, $\rho$ is the distance between robot and obstacle, $\rho_{0}$ is the robot minimal distance which has a repulsive effect.

The distance between robot and obstacle $\rho$ is

$$
\rho=\sqrt{\left(\mathbf{x}-\mathbf{x}_{\mathbf{0}}\right)^{2}}=\sqrt{\left(x-x_{o}\right)^{2}+\left(y-y_{o}\right)^{2}}
$$

Where $\mathbf{x}_{\mathbf{0}}=\left[\begin{array}{ll}x_{O} & y_{O}\end{array}\right]^{T}$ is the obstacle position vector.

The repulsive force is the gradient of the repulsive potential function as

$$
\begin{gathered}
F_{r e p}(\mathbf{x})=-\nabla U_{r e p}(\mathbf{x}) \\
F_{r e p}(\mathbf{x})=\left\{\begin{array}{rr}
-k_{r}\left(\frac{1}{\rho}-\frac{1}{\rho_{0}}\right) \frac{1}{\rho^{2}} \frac{\partial \rho}{\partial \mathbf{x}}, & \text { if } \rho \leq \rho_{0} \\
0, & \text { if } \rho>\rho_{0}
\end{array}\right.
\end{gathered}
$$

where

$$
\frac{\partial \rho}{\partial \mathbf{x}}=\left[\begin{array}{ll}
\frac{\partial \rho}{\partial x} & \frac{\partial \rho}{\partial y}
\end{array}\right]^{T}=\frac{\mathbf{x}_{O}-\mathbf{x}}{\rho},
$$

where, $\mathbf{x}_{O}$ is the position obstacle in $x y$-coordinate system.

Rizqi et al. [47] defined a modified artificial potential field with the repulsive force in (3) as

$$
\begin{gathered}
F_{r e p}(\mathbf{x})=-\nabla U_{r e p}(\mathbf{x}) \\
=\left\{\begin{aligned}
-k_{r}\left(\frac{1}{\rho_{m}}-\frac{1}{\rho_{0}}\right) \frac{1}{\left(\rho_{m}\right)^{2}}, & \text { if } \rho \leq \rho_{m} \\
-k_{r}\left(\frac{1}{\rho}-\frac{1}{\rho_{0}}\right)\left(\frac{\mathbf{x}_{O}-\mathbf{x}}{\rho^{3}}\right), & \text { if } \rho_{m}<\rho<\rho_{0} \\
0, & \text { if } \rho>\rho_{0}
\end{aligned}\right.
\end{gathered}
$$

where $\rho_{m}$ is the minimal distance where the force is constant.

Sun et al. [48] proposed about optimized artificial potential field algorithm. The repulsive field function is

$$
\begin{aligned}
& U_{\text {rep }}(\mathbf{x}) \\
& =\left\{\begin{aligned}
\frac{1}{2} k_{r}\left(\frac{1}{\rho}-\frac{1}{\rho_{0}}\right)^{2}\left(\mathbf{x}-\mathbf{x}_{d}\right)^{n}, & \text { if } \rho \leq \rho_{0} . \\
0, & \text { if } \rho>\rho_{0}
\end{aligned}\right.
\end{aligned}
$$

The repulsive force is

$$
F_{r e p}(\mathbf{x})=\left\{\begin{aligned}
F_{r e p_{1}}(\mathbf{x})+F_{\text {rep } 2}(\mathbf{x}), & \text { if } \rho \leq \rho_{0} \\
0, & \text { if } \rho>\rho_{0}
\end{aligned}\right.
$$

where 


$$
\begin{gathered}
F_{r e p 1}(\mathbf{x})=-k_{r}\left(\frac{1}{\rho(x)}-\frac{1}{\rho_{0}}\right) \frac{1}{\rho^{2}(x)}\left(\mathbf{x}-\mathbf{x}_{d}\right)^{n} \frac{\partial_{\rho}(\mathbf{x})}{\partial(\mathbf{x})} \\
F_{r e p 2}(\mathbf{x})=-\frac{n}{2} k_{r}\left(\frac{1}{\rho(x)}-\frac{1}{\rho_{0}}\right)^{2}\left(\mathbf{x}-\mathbf{x}_{d}\right)^{n-1} \frac{\partial\left(\mathbf{x}-\mathbf{x}_{d}\right)}{\partial(\mathbf{x})}
\end{gathered}
$$

where

$$
\begin{gathered}
\left(\mathbf{x}-\mathbf{x}_{d}\right)^{n}=\left|\left(x-x_{d}\right)^{n}\right|+\left|\left(y-y_{d}\right)^{n}\right| \\
\frac{\partial_{\rho}(\mathbf{x})}{\partial(\mathbf{x})}=\frac{\mathbf{x}-\mathbf{x}_{O}}{\rho(\mathbf{x})} \\
\frac{\partial\left(\mathbf{x}-\mathbf{x}_{d}\right)}{\partial(\mathbf{x})}=\frac{\mathbf{x}-\mathbf{x}_{O}}{\mathbf{x}-\mathbf{x}_{d}}
\end{gathered}
$$

where the variables $F_{\text {rep } 1}(\mathbf{x})$ and $F_{\text {rep } 2}(\mathbf{x})$ are twocomponent forces of $F_{\text {rep }}(\mathbf{x})$. The variable $n$ is constant value such as $n=0,0.5,1,2$.

The repulsive force with virtual force algorithm is proposed in [49] that was used to avoid the local minima. It can be written as

$$
F_{\text {rep }}(\mathbf{x})=\left\{\begin{aligned}
F_{r e p_{1}}(\mathbf{x})+F_{\text {vir }}(\mathbf{x}), & \text { if } \rho \leq \rho_{0} \\
0, & \text { if } \rho>\rho_{0}
\end{aligned}\right.
$$

where

$$
\begin{gathered}
F_{r e p 1}(\mathbf{x})=-k_{r}\left(1-\frac{\rho}{\rho_{0}}\right)\left(\frac{\mathbf{x}_{O}-\mathbf{x}}{\rho^{3}}\right) \\
F_{v i r}(\mathbf{x})=-k_{v} \frac{1}{\rho}
\end{gathered}
$$

where $k_{v}$ is the virtual force gain.

\section{Total Force of APF}

The total force of APF is the sum of the attractive force and the repulsive force of $n$ obstacles as

$$
F_{\text {total }}(\mathbf{x})=F_{a t t}(\mathbf{x})+\sum_{i=1}^{n} F_{r e p_{i}}(\mathbf{x})
$$

The total force will be a set point reference for the quadrotor in $x$-axis and $y$-axis, respectively, as

$$
\begin{aligned}
& F_{\text {total_x }}(\mathbf{x})=F_{a t t_{\_} x}(\mathbf{x})+F_{\text {rep_o }}(\mathbf{x}) \\
& F_{\text {total_y }}(\mathbf{x})=F_{\text {att_y }}(\mathbf{x})+F_{\text {rep_y }}(\mathbf{x})
\end{aligned}
$$

\section{SimULATION RESUlT}

The simulation used the Simulink Matlab. In this section, some examinations were conducted. The first examination is about local minima in one obstacle. The second examination focused on local minima in two obstacles. Last, the third examination is about the goal not reachable (GNRON). The methods that will be compared are the traditional artificial potential field, modified artificial potential field, optimized artificial potential field, and artificial potential field with wall following. Finally, the analysis will conclude whether the UAV can avoid the obstacle and reach the goal.

\section{A. Local Minima in One Obstacle}

In the sub-section, local minima in one obstacle examination is presented. The result is shown in Fig. 2. The starting position was used in $(-7,-7)$, and the goal position was in $(8,8)$. The obstacle position is in $(0,0)$. It can be known that all of the algorithms can make the robot reaching the goal position.

\section{B. Local Minima in Two Obstacle}

In the sub-section, local minima with two obstacles examinations are presented. The result is shown in Fig. 3. The obstacle position is in $(-1,1)$ and $(1,-1)$. Based on the result, the traditional APF and modified APF cannot make the robot reach the goal position. It is because of the local minima located in front of the two obstacles. Meanwhile, the optimized APF and APF with virtual force can make the quadrotor reach the goal position.

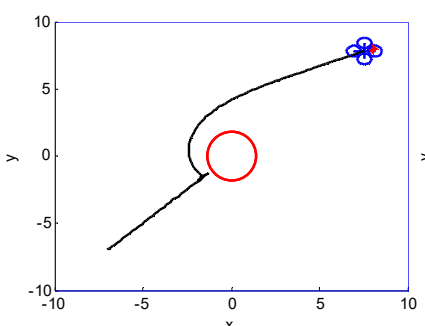

(a)

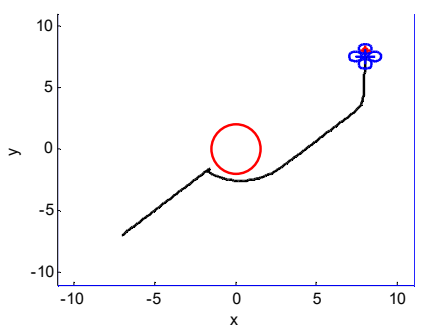

(c)

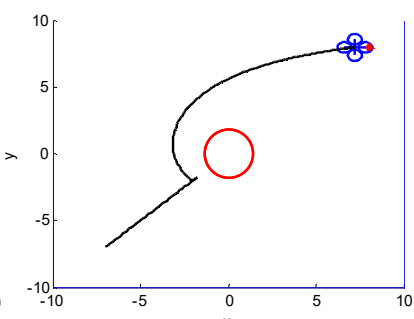

(b)

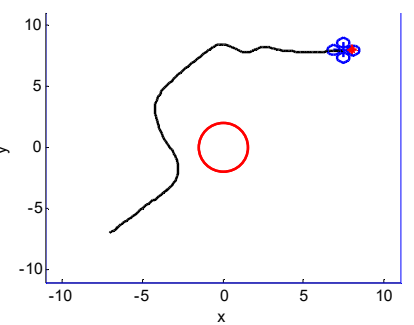

(d)
Fig. 2. One Obstacle Result (a) traditional APF (b) modified APF (c) optimized APF (d) APF with virtual force

\section{Goal not Reachable (GNRON)}

In the sub-section, examination for local minima in goal not reachable (GNRON) is presented in Fig. 4. The obstacle position is near the goal position. The goal is in the coordinate of $(8,8)$, and the obstacle is in the coordinate of $(6,6)$. It can be shown that the traditional APF and the modified APF can avoid the obstacle. However, it cannot reach the goal because the repulsive from the obstacle makes the quadrotor unable to reach the goal.

\section{Dynamic Obstacle}

In the sub-section, examination for local minima in goal not reachable (GNRON) is presented in Fig. 5. The static obstacle position is in the coordinate $(0,-1)$ and the dynamic 
obstacle is moving from the coordinate $(6,4)$ with horizontal movement. The goal is in the coordinate of $(8,8)$. It can be known that all of the algorithms can make the robot avoid the static and dynamic obstacle then reaching the goal position.

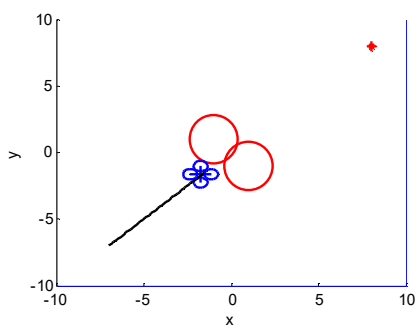

(a)

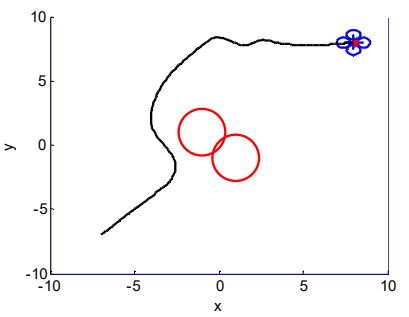

(c)

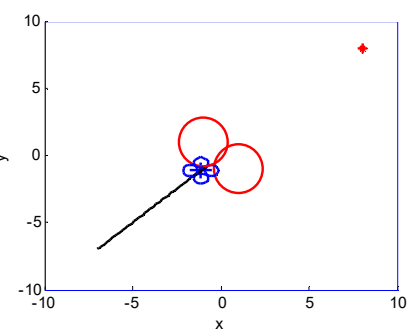

(b)

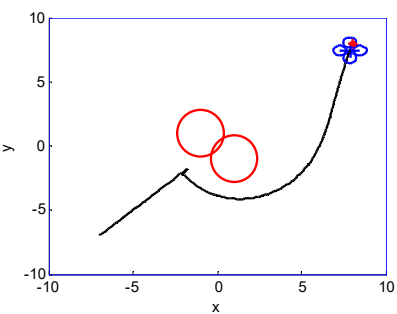

(d)
Fig. 3. Two Obstacle Result (a) traditional APF (b) modified APF (c) optimized APF (d) APF with virtual force

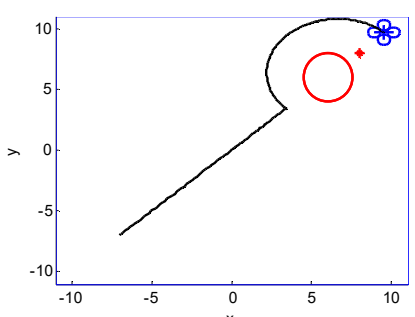

(a)

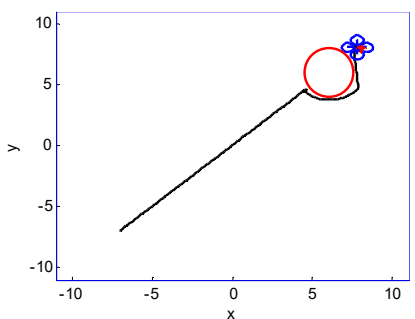

(c)

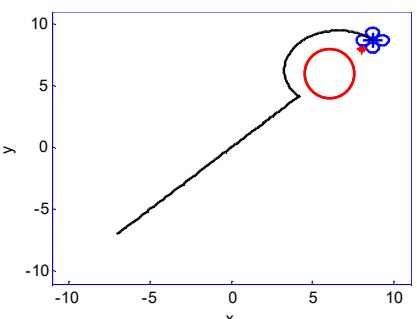

(b)

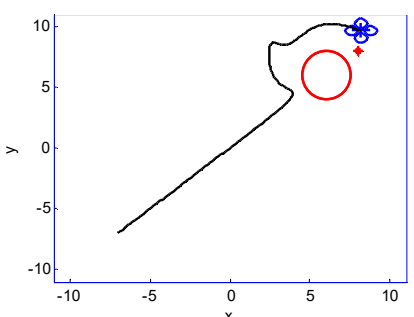

(d)
Fig. 4. Two Obstacle Result (a) traditional APF (b) modified APF (c) optimized APF (d) APF with virtual force

\section{DISCUSSION}

The time to reach the goal position is shown in Table 1. In local minima with one and two obstacles, the Virtual Force APF has the fastest time to reach the Goal however has a problem in GNRON. It can be known that the optimized APF can reach goals in each examination. There is a reason why the optimized APF can reach the goal in GNRON. It can be seen in Table 2 based on each APF formula in (5), (7), (9), and (10). The optimized APF has $\left(\mathbf{x}-\mathbf{x}_{d}\right)$ distance from robot and goal parameter in repulsive force equation. Thus, if the goal is closest to the obstacle, then the parameter will decrease the repulsive force to make the robot reach the goal. Meanwhile, the APF with virtual force can have the fastest time reaching the goal because the virtual force will push the robot to the side when the robot is near the obstacle.

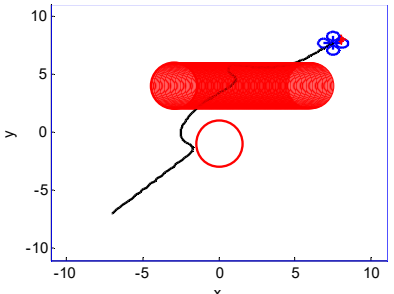

(a)

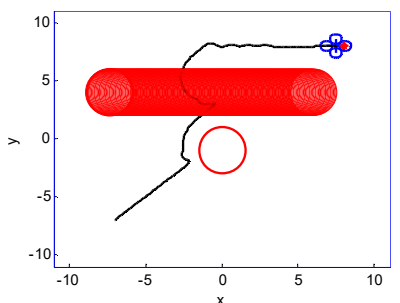

(c)

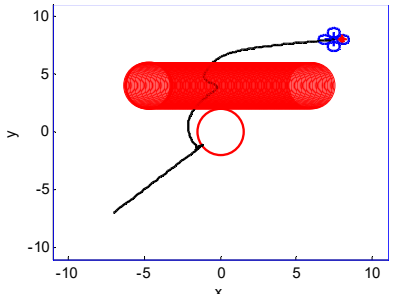

(b)

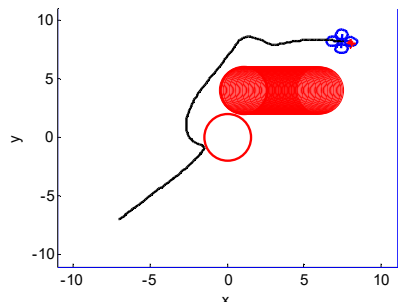

(d)
Fig. 5. Dynamic Obstacle Result (a) traditional APF (b) modified APF (c) optimized APF (d) APF with virtual force

TABLE I. TIME TO REACH GOAL

\begin{tabular}{|c|c|c|c|c|}
\hline \multirow{2}{*}{ Algorithm } & \multicolumn{3}{|c|}{ Examination } & \\
\cline { 2 - 5 } & $\begin{array}{c}\text { One } \\
\text { Obstacle }\end{array}$ & $\begin{array}{c}\text { Two } \\
\text { Obstacle }\end{array}$ & GNRON & $\begin{array}{c}\text { Dynamic } \\
\text { Obstacle }\end{array}$ \\
\hline Traditional APF & $6.370 \mathrm{~s}$ & - & - & $5.948 \mathrm{~s}$ \\
\hline Modified APF & $6189 \mathrm{~s}$ & - & - & $5.944 \mathrm{~s}$ \\
\hline Optimized APF & $9.514 \mathrm{~s}$ & $12.818 \mathrm{~s}$ & $11.614 \mathrm{~s}$ & $8.962 \mathrm{~s}$ \\
\hline Virtual Force APF & $3.523 \mathrm{~s}$ & $4.507 \mathrm{~s}$ & - & $3.249 \mathrm{~s}$ \\
\hline
\end{tabular}

TABLE II. REPULSIVE FORCE COMPONENT

\begin{tabular}{|c|c|c|c|}
\hline \multirow{2}{*}{ Algorithm } & \multicolumn{3}{|c|}{ Repulsive Force Component } \\
\cline { 2 - 4 } & $\boldsymbol{\rho}$ & $\left(\mathbf{x}-\mathbf{x}_{\boldsymbol{d}}\right)$ & $\boldsymbol{F}_{\text {vir }}$ \\
\hline Traditional APF & $\mathrm{v}$ & - & - \\
\hline Modified APF & $\mathrm{v}$ & - & - \\
\hline Optimized APF & $\mathrm{v}$ & $\mathrm{V}$ & - \\
\hline Virtual Force APF & $\mathrm{v}$ & - & $\mathrm{V}$ \\
\hline
\end{tabular}

\section{CONCLUSIONS}

The research proposes a performance comparison of Artificial Potential Field (APF) algorithms in UAV quadrotor in one obstacle local minima, two obstacle local minima, and GNRON. As a result, the optimized APF can reach goals in all of the examinations. Furthermore, the distance parameter between the robot and goal in repulsive force can decrease the repulsive force. The fastest method to reach the goal is APF with virtual force, but it still has a problem in GNRON. The Artificial Potential Field is suitable for robot navigation but still needs modification to pass all of the local minima problems. The important parameter in repulsive APF is the distance between robot and goal, and virtual force. 


\section{ACKNOWLEDGMENT}

The author would like to deliver thanks to the editor and reviewer for their advice, suggestion, and comment. Also, for help, the manuscript until the manuscript is published. The research is support by part of research fundamentals funding Universitas Ahmad Dahlan grant.

\section{REFERENCES}

[1] M. Wardani and A. Yudhana, "Rancang Bangun Penyemprot Pestisida untuk Pertanian Padi Berbasis Quadcopter," Jurnal Ilmiah Teknik Elektro Komputer dan Informatika, vol. 3, no. 2, p. 132, Jan. 2018.

[2] X. Zhang, X. Li, K. Wang, and Y. Lu, "A survey of modelling and identification of quadrotor robot," Abstract and Applied Analysis, vol. 2014. Hindawi Publishing Corporation, 2014.

[3] A. C. Subrata, "Automatic Landing And Waypoint System Berbasis Kombinasi GPS dan Mesin Visi untuk Multirotor pada Kontes Robot Terbang Indonesia Divisi Vertical Take Off Landing,” Jurnal Ilmiah Teknik Elektro Komputer dan Informatika, vol. 2, no. 2, p. 110, Dec. 2017.

[4] M. I. Faiq Hatta and N. Satya Widodo, "Robot Operating System (ROS) in Quadcopter Flying Robot Using Telemetry System," International Journal of Robotics and Control Systems, vol. 1, no. 1, pp. 54-65, 2021.

[5] S. A. Akbar, A. Yudhana, and A. S. Nugroho, "Citra Kawasan Konservasi Penyu Pesisir Pantai Yogyakarta Menggunakan Foto Udara Berbasis EmguCV," Jurnal Ilmiah Teknik Elektro Komputer dan Informatika, vol. 4, no. 2, p. 1, Jan. 2019.

[6] P. A. Rosyady and R. Sumiharto, "Highway Visual Tracking System using Thresholding and Hough Transform," Jurnal Ilmiah Teknik Elektro Komputer dan Informatika, vol. 4, no. 2, pp. 93-99, 2018.

[7] D. M. Harfina, Z. Zaini, and W. J. Wulung, "Disinfectant Spraying System with Quadcopter Type Unmanned Aerial Vehicle Technology as an Effort to Break the Chain of the COVID-19 Virus," Journal of Robotics and Control (JRC), vol. 2, no. 6, pp. 502-507, 2021.

[8] F. Bounini, D. Gingras, H. Pollart, and D. Gruyer, "Modified artificial potential field method for online path planning applications," in IEEE Intelligent Vehicles Symposium, Proceedings, 2017, pp. 180-185.

[9] N. He, Y. Su, J. Guo, X. Fan, Z. Liu, and B. Wang, "Dynamic path planning of mobile robot based on artificial potential field," in 2020 International Conference on Intelligent Computing and HumanComputer Interaction (ICHCI), 2021, pp. 259-264.

[10] J.-F. Duhé, S. Victor, K. Ruiz, and P. Melchior, "Study on obstacle avoidance for fractional artificial potential fields," IFACPapersOnLine, vol. 53, no. 2, pp. 3725-3730, Jan. 2020.

[11] A. Pandey, S. Kumar, K. K. Pandey, and D. R. Parhi, "Mobile robot navigation in unknown static environments using ANFIS controller," Perspectives in Science, vol. 8, pp. 421-423, Sep. 2016.

[12] U. Orozco-Rosas, O. Montiel, and R. Sepúlveda, "Mobile robot path planning using membrane evolutionary artificial potential field," Applied Soft Computing Journal, vol. 77, pp. 236-251, Apr. 2019.

[13] T. T. Mac, C. Copot, D. T. Tran, and R. De Keyser, "Heuristic approaches in robot path planning: A survey," Robotics and Autonomous Systems, vol. 86, pp. 13-28, Dec. 2016.

[14] B. K. Patle, G. Babu L, A. Pandey, D. R. K. Parhi, and A. Jagadeesh,
"A review: On path planning strategies for navigation of mobile robot," Defence Technology, vol. 15, no. 4, pp. 582-606, Aug. 2019.

[15] M. N. Zafar and J. C. Mohanta, "Methodology for Path Planning and Optimization of Mobile Robots: A Review," Procedia Computer Science, vol. 133, pp. 141-152, Jan. 2018.

[16] J. Liu, J. Yang, H. Liu, X. Tian, and M. Gao, “An improved ant colony algorithm for robot path planning," Soft Computing, vol. 21, no. 19, pp. 5829-5839, Oct. 2017.

[17] J. Da Silva Arantes, M. Da Silva Arantes, C. F. M. Toledo, O. T. Júnior, and B. C. Williams, "Heuristic and Genetic Algorithm Approaches for UAV Path Planning under Critical Situation," International Journal on Artificial Intelligence Tools, vol. 26, no. 1, Feb. 2017.

[18] C. Lamini, S. Benhlima, and A. Elbekri, "Genetic algorithm based approach for autonomous mobile robot path planning," in Procedia Computer Science, 2018, vol. 127, pp. 180-189.

[19] G. Li and W. Chou, "Path planning for mobile robot using self-adaptive learning particle swarm optimization," Science China Information Sciences, vol. 61, no. 5, pp. 1-18, May 2018.

[20] J. H. Zhang, Y. Zhang, and Y. Zhou, "Path planning of mobile robot based on hybrid multi-objective bare bones particle swarm optimization with differential evolution," IEEE Access, vol. 6, pp. 44542-44555, Aug. 2018.

[21] X. Yu, C. Li, and J. F. Zhou, "A constrained differential evolution algorithm to solve UAV path planning in disaster scenarios," Knowledge-Based Systems, vol. 204, p. 106209, Sep. 2020.

[22] U. Orozco-Rosas, K. Picos, and O. Montiel, "Hybrid Path Planning Algorithm Based on Membrane Pseudo-Bacterial Potential Field for Autonomous Mobile Robots," IEEE Access, vol. 7, pp. 156787156803, 2019.

[23] Y. Zhao, Z. Zheng, and Y. Liu, "Survey on computational-intelligencebased UAV path planning," Knowledge-Based Systems, vol. 158, pp. 54-64, Oct. 2018.

[24] Q. Yao et al., "Path Planning Method with Improved Artificial Potential Field - A Reinforcement Learning Perspective," IEEE Access, vol. 8, pp. 135513-135523, 2020.

[25] J. H. Cho, D. S. Pae, M. T. Lim, and T. K. Kang, "A Real-Time Obstacle Avoidance Method for Autonomous Vehicles Using an Obstacle-Dependent Gaussian Potential Field," Journal of Advanced Transportation, vol. 2018, 2018.

[26] O. Khatib, "Real-Time Obstacle Avoidance for Manipulators and Mobile Robots," The International Journal of Robotics Research, vol. 5, no. 1, pp. 90-98, Mar. 1986.

[27] O. Khatib, "Real-time obstacle avoidance for manipulators and mobile robots," in Proceedings - IEEE International Conference on Robotics and Automation, 1985, pp. 500-505.

[28] M. Zhao and X. Lv, "Improved Manipulator Obstacle Avoidance Path Planning Based on Potential Field Method," Journal of Robotics, vol. 2020, 2020.

[29] A. Azzabi and K. Nouri, "An advanced potential field method proposed for mobile robot path planning," Transactions of the Institute of Measurement and Control, vol. 41, no. 11, pp. 3132-3144, Jul. 2019.

[30] G. Chen and J. Liu, "Mobile Robot Path Planning Using Ant Colony Algorithm and Improved Potential Field Method," Computational 
Intelligence and Neuroscience, vol. 2019, 2019.

[31] S. M. H. Rostami, A. K. Sangaiah, J. Wang, and X. Liu, "Obstacle avoidance of mobile robots using modified artificial potential field algorithm," Eurasip Journal on Wireless Communications and Networking, vol. 2019, no. 1, pp. 1-19, Dec. 2019.

[32] T. T. Mac, C. Copot, A. Hernandez, and R. De Keyser, "Improved potential field method for unknown obstacle avoidance using UAV in indoor environment," in SAMI 2016 - IEEE 14th International Symposium on Applied Machine Intelligence and Informatics Proceedings, 2016, pp. 345-350.

[33] X. Xu, Y. Hu, J. M. Zhai, L. Z. Li, and P. S. Guo, "A novel noncollision trajectory planning algorithm based on velocity potential field for robotic manipulator," International Journal of Advanced Robotic Systems, vol. 15, no. 4, Jul. 2018.

[34] Z. Chen, L. Ma, and Z. Shao, "Path Planning for Obstacle Avoidance of Manipulators Based on Improved Artificial Potential Field," in Proceedings - 2019 Chinese Automation Congress, CAC 2019, 2019, pp. 2991-2996.

[35] P. B. Kumar, H. Rawat, and D. R. Parhi, "Path planning of humanoids based on artificial potential field method in unknown environments," Expert Systems, vol. 36, no. 2, p. e12360, Apr. 2019.

[36] S. Wang, T. Zhao, and W. Li, "Mobile Robot Path Planning Based on Improved Artificial Potential Field Method," in 2018 IEEE International Conference of Intelligent Robotic and Control Engineering, IRCE 2018, 2018, pp. 257-262.

[37] X. Lin, Z. Q. Wang, and X. Y. Chen, "Path Planning with Improved Artificial Potential Field Method Based on Decision Tree," in 27th Saint Petersburg International Conference on Integrated Navigation Systems, ICINS 2020 - Proceedings, 2020.

[38] Y. Liu and Y. Zhao, "A virtual-waypoint based artificial potential field method for UAV path planning," in CGNCC 2016 - 2016 IEEE Chinese Guidance, Navigation and Control Conference, 2017, pp. 949-953.

[39] E. Wu, Y. Sun, J. Huang, C. Zhang, and Z. Li, "Multi UAV Cluster Control Method Based on Virtual Core in Improved Artificial Potential Field," IEEE Access, vol. 8, pp. 131647-131661, 2020.

[40] P. Wang, S. Gao, L. Li, B. Sun, and S. Cheng, "Obstacle Avoidance Path Planning Design for Autonomous Driving Vehicles Based on an Improved Artificial Potential Field Algorithm," Energies 2019, Vol. 12, Page 2342, vol. 12, no. 12, p. 2342, Jun. 2019.

[41] Y. Shin and E. Kim, "Hybrid path planning using positioning risk and artificial potential fields," Aerospace Science and Technology, vol. 112, p. 106640, May 2021.

[42] X. Fan, Y. Guo, H. Liu, B. Wei, and W. Lyu, "Improved Artificial Potential Field Method Applied for AUV Path Planning," Mathematical Problems in Engineering, vol. 2020, 2020.

[43] O. Montiel, U. Orozco-Rosas, and R. Sepúlveda, "Path planning for mobile robots using Bacterial Potential Field for avoiding static and dynamic obstacles," Expert Systems with Applications, vol. 42, no. 12, pp. 5177-5191, Jul. 2015.

[44] C. C. Barros Viturino, U. de Melo Pinto Junior, A. Gustavo Scolari Conceição, and L. Schnitman, "Adaptive Artificial Potential Fields with Orientation Control Applied to Robotic Manipulators," IFACPapersOnLine, vol. 53, no. 2, pp. 9924-9929, Jan. 2020.

[45] K. Lee, D. Choi, and D. Kim, "Incorporation of Potential Fields and Motion Primitives for the Collision Avoidance of Unmanned Aircraft," Applied Sciences 2021, Vol. 11, Page 3103, vol. 11, no. 7, p. 3103, Mar. 2021.

[46] Y. B. Chen, G. C. Luo, Y. S. Mei, J. Q. Yu, and X. L. Su, "UAV path planning using artificial potential field method updated by optimal control theory," International Journal of Systems Science, vol. 47, no. 6, pp. 1407-1420, Apr. 2016.

[47] A. A. A. Rizqi, A. I. Cahyadi, and T. B. Adji, "Path planning and formation control via potential function for UAV Quadrotor," in 2014 International Conference on Advanced Robotics and Intelligent Systems, ARIS 2014, 2014, pp. 165-170.

[48] J. Sun, J. Tang, and S. Lao, "Collision Avoidance for Cooperative UAVs with Optimized Artificial Potential Field Algorithm," IEEE Access, vol. 5, pp. 18382-18390, Aug. 2017.

[49] Iswanto, A. Ma'arif, O. Wahyunggoro, and A. I. Cahyadi, "Artificial potential field algorithm implementation for quadrotor path planning," International Journal of Advanced Computer Science and Applications, vol. 10, no. 8, pp. 575-585, 2019.

[50] Y. Li, H. Yao, H. Yu, F. He, and Y. Yao, "An improved APF-based path planning algorithm for a quadrotor intercepting autonomous ground robots," in Chinese Control Conference, CCC, 2019, vol. 2019July, pp. 4772-4777.

[51] M. Shang, M. Chu, and M. Grethler, "Path Planning Based on Artificial Potential Field and Fuzzy Control," in Proceedings - 2020 International Conference on Intelligent Computing, Automation and Systems, ICICAS 2020, 2020, pp. 304-308.

[52] N. Rinanto, I. Marzuqi, A. Khumaidi, and S. T. Sarena, "Obstacle Avoidance using Fuzzy Logic Controller on Wheeled Soccer Robot," Jurnal Ilmiah Teknik Elektro Komputer dan Informatika, vol. 5, no. 1, pp. 26-35, 2019.

[53] N. S. Özbek, M. Önkol, and M. Ö. Efe, "Feedback control strategies for quadrotor-type aerial robots: A survey," in Transactions of the Institute of Measurement and Control, 2016, vol. 38, no. 5, pp. 529554.

[54] Q. Li, J. Yuan, B. Zhang, and H. Wang, "Artificial potential field based robust adaptive control for spacecraft rendezvous and docking under motion constraint," ISA Transactions, vol. 95, pp. 173-184, Dec. 2019.

[55] S. Feng, Y. Qian, and Y. Wang, "Collision avoidance method of autonomous vehicle based on improved artificial potential field algorithm," Proceedings of the Institution of Mechanical Engineers, Part D: Journal of Automobile Engineering, p. 095440702110143, Apr. 2021. 